\title{
New dietary records for croaking lizards of the genus Aristelliger (Reptilia: Sphaerodactylidae)
}

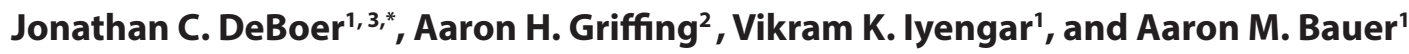 \\ 'Department of Biology, Villanova University, 800 Lancaster Avenue, Villanova, Pennsylvania 19085, USA. \\ ${ }^{2}$ Department of Biological Sciences, Marquette University, $530 \mathrm{~N}$ 15th St., Milwaukee, Wisconsin 53233, USA. \\ Current Address: ${ }^{3}$ Department of Geography, University of Nevada, Reno, 1664 N. Virginia St., Reno, Nevada 89557, USA. \\ ${ }^{*}$ Corresponding author (jdeboer@nevada.unr.edu)
}

Associate Editor: Robert W. Henderson. Date of publication: 5 September 2018.

Citation: DeBoer JC, Griffing AH, lyengar VK, Bauer AM (2018) New dietary records for croaking lizards of the genus Aristelliger (Reptilia: Sphaerodactylidae). Caribbean Herpetology, 62, 1-8.

DOI: $10.31611 /$ ch.62

\begin{abstract}
Croaking Lizards (Aristelliger) are some of the largest geckos occurring in the New World, but knowledge of their basic biology remains limited. Here we present a dietary account of Aristelliger. Our results augment existing data by providing new dietary records for seven of the nine species of Aristelliger. The first dietary records are reported for three of these species (A. barbouri, A. expectatus, and A. hechti). We report lithophagy, frugivory, seed dispersal, and ontogenetic variation in the diet of Aristelliger and the first instance of molluscivory in the genus. In total, 22 items were added to the dietary records of various species of Aristelliger with nine items being new to the genus.
\end{abstract}

Keywords: Caribbean, frugivory, gecko, lithophagy, molluscivory.

\section{Introduction}

Aristelliger is a genus of vocal sphaerodactylid geckos that are distributed throughout the West Indies and sporadically along Central America's Atlantic coast and some satellite islands (Hecht 1952; Schwartz \& Henderson 1991; Bauer \& Russell 1993). Unlike most New World sphaerodactylids, Aristelliger are nocturnal, semi-arboreal, and exhibit a range of body sizes, with most species being relatively large (Schwartz \& Henderson 1991; Bauer \& Russell 1993; Henderson \& Powell 2009). Aristelliger are omnivorous and known to eat a diversity of prey items (Henderson \& Powell 2009). However, data on natural diets are available for only half of the described species (A. cochranae, A. lar, A. praesignis, and A. reyesi) and only A. cochranae and A. lar are represented by more than minimal dietary records (Schwartz \& Henderson 1991; Gifford et al. 2000).

\section{Materials and Methods}

We examined specimens collected during fields trips to Great Inagua Island, Bahamas, and Jamaica (July 2015 and May 2016, respectively), as well as from a number of specimens in American museum collections (AMB, personal collection of Aaron M. Bauer, Villanova University, Villanova, Pennsylvania; KU, University of Kansas Natural History Museum, Lawrence, Kansas; MCZ, Museum of Comparative Zoology, Harvard University, Cambridge, Massachusetts; UCM, University of Colorado Museum of Natural History, Boulder, Colorado).

We made ventral incisions and dissected 59 preserved specimens (four A. barbouri, four A. cochranae, five $A$. expectatus, five $A$. georgeensis, two $A$. hechti, four $A$. lar, and 35 A. praesignis). We recorded sex and measured snout-vent length (SVL) of all inspected specimens with calipers to the nearest $0.1 \mathrm{~mm}$ (Appendix 1), examined stomach and intestinal contents under a dissecting scope, and isolated and stored gut contents in 
$70 \%$ ethanol. We identified dietary items to order or family, although several items could be identified more precisely. We did not count prey items as many were highly fragmented.

\section{Results}

Aristelliger examined comprised 23 males, 28 females, and 9 unsexed specimens representing a range of both adults and juveniles (Table 1). Forty-three of the 59 Aristelliger examined contained ingested items in the stomach and/or intestines. We extracted 88 different items allocated to 22 dietary categories (Table 2). Most items in the intestines were digested and could only be identified through hard body parts (e.g., head capsules, mandibles, elytra, and legs).

The majority of prey categories were

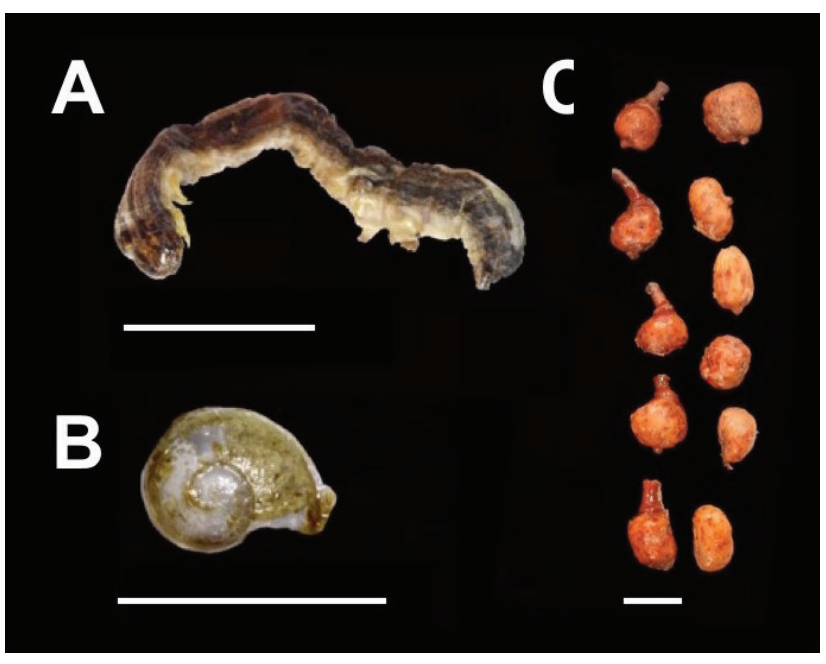

Figure 1. Various dietary items of Aristelliger. A) Typical lepidopteran larva found in the stomachs of Aristelliger praesignis. B) Pleurodontid snail, likely Thelidomus aspera, extracted from the stomach of an adult female A. praesignis (MCZ R 194565). C) Marcgraviacea fruit, likely Marcgravia domingensis, extracted from both the stomach and intestines of an adult male $A$. lar (KU 228785). Scale bars $=1 \mathrm{~cm}$. Arthropoda $(16 ; 76 \%)$. Important prey types (four over $25 \%$ of specimens that contained ingested items) were representative of Araneae, Coleoptera, Hymenoptera, Lepidoptera (Fig. 1A), and Orthoptera. Additional dietary items included a species of pleurodontid snail, likely Thelidomus aspera (Fig. 1B), and plant material found in three specimens of two species, most notably fruits, likely from Marcgraviacea: Marcgravia domingensis (Fig. 1C). We found small stones in three specimens.

The following paragraphs provide dietary summaries and relevant information by species.

Aristelliger barbouri Nobel \& Klingel, 1932. This is a medium-sized ( $46 \mathrm{~mm}$ maximum SVL), secretive, xerophilic species native to Great Inagua Island, Little Inagua Island, and Sheep Cay, Bahamas (Nobel \& Klingel 1932; Schwartz \& Henderson 1991). No previous dietary records were available for A. barbouri. Araneae, Coleoptera, Heteroptera, Lepidoptera, and Orthoptera are reported here as the first dietary records for the species.

Aristelliger cochranae Grant, 1931. This is a medium-sized (63 mm maximum SVL), xerophilic species native to Navassa Island (Schwartz \& Henderson 1991). This species has the most extensive dietary records of any member of the genus. Gifford et al. (2000) extracted 50 individual prey items from specimens from Navassa Island. They reported cannibalism, finding both hatchlings and eggs among the stomach contents of multiple adult female A. cochranae. The remaining items consisted of Arachnida: Araneida and Pseudoscorpionida; Insecta: Blattodea: Blattelidae; Coleoptera: Anobiidae, Scolytidae, and Tenebriondae; Diptera; Hymenoptera: Formicidae; Isoptera; and Lepidoptera: Gelechiidae. Hemiptera, Odonata, and Orthoptera are new dietary items for A. cochranae, increasing the known dietary items from 12 to 15 different prey types.

Aristelliger expectatus Cochran, 1933. This is a medium-sized (55 mm maximum SVL), xerophilic species native to western Hispaniola (Thomas 1966; Henderson \& Powell 2009). No previous dietary records were available for A. expectatus. Orthoptera: Gryllidae is the first and only dietary record for A. expectatus.

Aristelliger georgeensis (Bocourt, 1873). This is a large (115 mm maximum SVL), mesophilic species and the only Aristelliger found on the Central American coast and some satellite islands (Dunn \& Saxe 1950; Hecht 1952; Bauer \& Russell 1993; Lee 1996). Dunn \& Saxe (1950) reported locals on Providencia stating that "the screeching lizard live in trees and eat tame lizards [Anolis]"; however, this remains unverified. The consumption of other vertebrates is rare among geckos, with most prey items being other geckos and conspecifics (Bauer 1990). Nonetheless, a prey item of this size seems feasible due to the large size of $A$. georgeensis. Aristelliger georgeensis also is known 
caribbean herpetology

article

Table 1. Species, sex ratios, and size of Aristelliger examined. Sex ratio, males:females:unsexed. SVL, snout-vent length.

\begin{tabular}{cccccc}
\hline Species & $\mathbf{n}$ & Sex ratio total & Sex ratio with contents & SVL range $(\mathbf{m m})$ & SVL average $(\mathbf{m m})$ \\
\hline A. barbouri & 4 & $0: 4: 0$ & $0: 3: 0$ & $36.7-41.6$ & 40.6 \\
A. cochranae & 4 & $1: 1: 2$ & $0: 0: 1$ & $26.9-58.2$ & 43.4 \\
A. expectatus & 5 & $0: 3: 2$ & $0: 1: 0$ & $17.2-52.8$ & 35.1 \\
A. georgeensis & 5 & $2.3: 0$ & $1: 3: 0$ & $33.6-95.6$ & 69.8 \\
A. hechti & 2 & $1: 1: 0$ & $1: 1: 0$ & $46.4-86.4$ & 66.4 \\
A. lar & 4 & $1: 2: 1$ & $1: 2: 0$ & $43.4-129.9$ & 77.1 \\
A. praesignis & 35 & $18: 14: 3$ & $14: 13: 1$ & $23.0-98.0$ & 68.8 \\
A. reyesi & 0 & - & - & - & - \\
\hline Total & 59 & $23: 28: 8$ & $17: 23: 2$ & $17.2-129.9$ & 63 \\
\hline
\end{tabular}

Table 2. Stomach and intestine contents of $\mathbf{4 2}$ specimens of Aristelliger. $(\dagger)$, new dietary item for the genus. $(*)$, new dietary item for the species. A. barbouri, Ab. A. cochranae, Ac. A. expectatus, Ae. A. georgeensis, Ag. A. hechti, Ah. A. lar, Al. A. praesignis, Ap.

\begin{tabular}{|c|c|c|c|c|c|c|c|}
\hline Dietary Item & $\mathbf{A b}$ & Ac & Ae & Ag & Ah & Al & Ap \\
\hline \multicolumn{8}{|l|}{ ARACHNIDA } \\
\hline Araneae & $3^{*}$ & 1 & & $1^{*}$ & & & 8 \\
\hline \multicolumn{8}{|l|}{ INSECTA } \\
\hline Blattoidea & & 1 & & & & & 1 \\
\hline Coleoptera & $1^{*}$ & & & & $1^{*}$ & & 9 \\
\hline Curculionoideat & & & & $1^{*}$ & & & \\
\hline Diptera & & & & & & & 6 \\
\hline Tephritidaet & & & & $1^{*}$ & & & \\
\hline \multicolumn{8}{|l|}{ Hemiptera } \\
\hline Heteroptera $†$ & $1^{*}$ & & & & & & \\
\hline Homoptera† & & $1^{*}$ & & & & & \\
\hline Hymenoptera & & & & & & & $4^{*}$ \\
\hline Apocritat & & & & & & & $1^{*}$ \\
\hline Formicidae & & & & $1^{*}$ & $1^{*}$ & & $9^{*}$ \\
\hline Lepidoptera & & & & & & & $2^{*}$ \\
\hline Lepidoptera (larvae) & $1^{*}$ & & & & & & $9^{*}$ \\
\hline Odonatat & & $1^{*}$ & & & & & \\
\hline Orthoptera & $1^{*}$ & 1 & & $3^{*}$ & & 1 & $2^{*}$ \\
\hline Acrididaet & & & & $1^{*}$ & & & \\
\hline Gryllidae & & & $1^{*}$ & $1^{*}$ & & & \\
\hline \multicolumn{8}{|l|}{ GASTROPODA } \\
\hline Pleurodontidaet & & & & & & & $3^{*}$ \\
\hline \multicolumn{8}{|l|}{ PLANT } \\
\hline Marcgraviat & & & & & & $1^{*}$ & \\
\hline Seeds & & & & & & & $1^{*}$ \\
\hline Misc. plant material & & & & & & 2 & \\
\hline \multicolumn{8}{|l|}{ OTHER CONTENTS } \\
\hline Stones & & $1^{*}$ & & & & & 2 \\
\hline
\end{tabular}

to eat scorpions in the wild (White et al. 2017) and its own shed skin (i.e., dermatophagy) in captivity (Weldon et al. 1993).

Araneae, Coleoptera: Curculionoidea, Hymenoptera: Formicidae, Orthoptera: Acrididae and Gryllidae, and Diptera: Tephritidae are new dietary items for this species, increasing the known dietary items from 3 to 9. Of particular interest was a specimen (UCM 16183) that contained at least 50 tephritids, several formicids, a curculionoid, and an orthopteran. The tephritids were found intact within the stomach. These tiny insects may be a more prevalent prey item in the diets of Aristelliger and other geckos, but may be overlooked due to their minuscule size and rapid rates of digestion. 
Aristelliger hechti Schwartz \& Crombie, 1975. This is a large (90 mm maximum SVL), xerophilic species native to the Caicos Islands (Schwartz \& Crombie 1975). No previous records of dietary items were available for $A$. hechti. We report Coleoptera (two unidentifiable species both found within KU 228757) and Hymenoptera: Formicidae as dietary items for $A$. hechti.

Aristelliger lar Cope, 1862. This is a large (135 mm maximum SVL), mesophilic species native to Hispaniola (Hecht 1952). The known dietary items of $A$. lar include: spiders, beetles, roaches, true bugs, crickets, ghost crabs, and a flower (Schwartz \& Henderson 1991; Burns et al. 1992; Henderson \& Powell 2009). Aristelliger lar appears to be omnivorous. Schwartz and Henderson (1991) reported seeds and fruits from a fecal examination, "spherical seeds (approx. $6 \mathrm{~mm}$ in diameter), and red pulp, also many tiny seeds (like strawberry achenes), and elongate (3/4 in.), many-seeded white fruits" (Henderson \& Powell 2009).

Our results are consistent with previous dietary data for $A$. lar. We confirm frugivory by a single individual (KU 228785) containing 11 Marcgraviaceae fruits, likely Marcgravia domingensis (Fig. 1C). The large quantity of fruits suggests that the consumption was not accidental. Marcgravia nectar and fruits also are consumed by Neotropical bats, opossums, frugivorous and nectivorous birds, and primates, the latter two of which are known seed dispersers (van Roosemalen 1985; Tschapka \& Helversen 1999; Zusi \& Hamas 2001; Herrera et al. 2003). Geckos, especially insular forms, are known to be important seed dispersers in some ecosystems (Whitaker 1987; Bauer \& Sadlier 1994; Wotton 2002; Olesen \& Valido 2003) and A. lar also might serve in this role.

Aristelliger nelsoni Barbour, 1914. This is a large (235 mm total length; Barbour 1914), mesophilic species native to the Swan Islands, Honduras (Barbour 1914). We did not examine any specimens of this species. No previous records of dietary items were available for A. nelsoni. McCranie et al. (2017) found an individual A. nelsoni inside a termite nest, suggesting that $\operatorname{diet}$ of $A$. nelsoni may include termites.

Aristelliger praesignis (Hallowell, 1856). This is a large (101 mm maximum SVL), mesophilic species native to Jamaica, and the Cayman Islands (Schwartz \& Henderson 1991; Griffing et al. 2017). Insects, including cockroaches, and sugar (Garman 1888; English 1912; Grant 1940; Schwartz \& Henderson 1991) have been reported in its diet.

We report eleven new dietary items for A. praesignis. Arthropodan prey were assignable to Araneae, Coleoptera, Diptera, Hymenoptera: Apocrita and Formicidae, Lepidoptera: adults and larvae, and Orthoptera. A large, unidentifiable seed found in KU 228974 is the second instance of an Aristelliger consuming large seeds, the first being A. lar (Schwartz \& Henderson 1991). Most significant is the first record of molluscivory in any Aristelliger. A subadult female $A$. praesignis (MCZ R 194565) contained an entire juvenile pleurodontid snail, likely Thelidomus aspera (Fig. 1B), and similar shell fragments were found in two other A. praesignis (MCZ R 194568, MCZ R 194587). Molluscivory, although uncommon in gekkotans as a whole (Paluh \& Bauer 2016), has previously been documented in several genera of small to miniaturized Neotropical sphaerodactylids (Coleodactylus, Gonatodes, Pseudogonatodes, and Sphaerodactylus; Daza et al. 2009). We found snail shells only in females, but other dietary items were recovered from both sexes.

Our data suggest ontogenetic variation in the diet of A. praesignis. Smaller A. praesignis consume smaller and slower moving prey, such as ants and lepidopteran larvae, whereas larger individuals consume larger prey items such as large Blattodea, Gryllidae, and Lepidoptera: adults (Appendix 1).

Aristelliger reyesi Díaz \& Hedges, 2009. This is a medium-sized (63.6 mm maximum SVL), largely xerophilic species endemic to Cuba (Díaz \& Hedges 2009). We did not examine any specimens of this species. Díaz \& Hedges (2009) reported ants (Camponotus sp.), neuropterans (adult), beetles, shed skin, and small stones from fecal material. Most of the dietary items are similar to those of other species of Aristelliger. Their report of shed skin is the first note of Aristelliger dermatophagy outside of captivity; however, dermatophagy is common among the majority of geckos (Bustard \& Maderson 1965; Welden et al. 1993). 


\section{Discussion}

Twenty-two new dietary items were identified for individual Aristelliger species and nine were new to the genus: Gastropoda: Pleurodontidae: Thelidomus aspera; Ericales: Marcgraviaceae: Marcgravia domingensis; Insecta: Coleoptera: Curculionoidea; Diptera: Tephritidae; Hemiptera: Heteroptera, and Homoptera; Hymenoptera: Apocrita; Odonata; and Orthoptera: Acrididae (Table 2).

This is the first published record of molluscivory in Aristelliger and the first to identify the genus of a fruit in the diet of Aristelliger. The large-bodied A. Iar likely is a seed disperser for the Marcgravia plant. Indeed, large body size often is considered a factor that facilitates frugivory (e.g., Schoener et al. 1982; Cooper \& Vitt 2002; Herrel et al. 2004). Further, our finding that $A$. lar eats plant material (KU 228785, KU 228792) and several fruits (KU 228785) and A. praesignis eats seeds (KU 228974) demonstrates that these species are using plant parts as an alternative food source to arthropods, which apparently is mediated by their large size.

Our large sample size of $A$. praesignis stomach contents revealed a possible ontogenetic shift in diet. Furthermore, our data suggest that a larger body size allows for a greater range of dietary items (Appendix 1). The relationship between body size and dietary items likely explains how the island of Hispaniola can support the sympatric species A. lar and A. expectatus (maximum 135 and $55 \mathrm{~mm} \mathrm{SVL}$, respectively). Further stomach content examination of $A$. expectatus is essential to determine if differences in diet contributed to dietary niche specialization between the Hispaniolan species.

Lastly, we extracted small stones from A. cochranae and A. praesignis. Individuals contained single or multiple stones. Ingested stones can indicate lithophagy, intentionally consuming small stones to aid in digestion. Sokol (1971) reported lithophagy in several lizard species and other reptiles that apparently ingest stones to macerate plant materials, such as fruit. Johnson (1966) indicated that stones in the stomachs of Sceloporus and Aspidoscelis were for the maceration of chitinous exoskeletons of arthropods. Three of nine Aristelliger species have records for ingesting stones, but robust dietary reports on $A$. barbouri, A. expectatus, and $A$. nelsoni are lacking. Díaz \& Hedges (2009) reported $A$. reyesi ingesting small stones, although they did not attribute it to accidental consumption or lithophagy. With a diet largely consisting of chitinous arthropods but also containing hard fruits and plant material, Aristelliger might be intentionally ingesting stones to aid in digestion.

\section{Acknowledgements}

We thank Drs. Gary Rosenberg (Academy of Natural Sciences at Drexel University) and Pedro Acevedo (Smithsonian Institution) for assistance in identifying mollusk and plant remains, respectively. We thank all institutional collections and associated curators and collection managers who loaned specimens to complete this study. Field collection of Aristelliger barbouri and A. praesignis was made possible by the Gerald Lemole Endowed Chair (Villanova University), Bahamas National Trust, Randolph Burrows, Jamaican National Environment and Planning Agen$c y$, and Dr. Byron Wilson (University of West Indies, Mona, Jamaica).

\section{References}

Barbour T (1914) A contribution to the zoogeography of the West Indies with special reference to amphibians and reptiles. Memoirs of the Museum of Comparative Zoology, 44, 205-359.

Bauer AM, Russell AP (1993) Aristelliger. Catalogue of American Amphibians and Reptiles, 565, 1-4.

Bauer AM, Sadlier RA (1994) Diet of the New Caledonian gecko Rhacodactylus auriculatus (Squamata, Gekkonidae). Russian Journal of Herpetology, 1, 108-113.

Burns JK, Cunningham CA, Dupuis RA, Trask MN, Tulloch JS, Powell R, Parmerlee JS Jr., Kopecky KL, Jolley ML (1992) Lizards of Cayos Siete Hermanos, Dominican Republic, Hispaniola. Bulletin of the Chicago Herpetological Society, 27, 225-232. 
Bustard HR, PFA Maderson (1965) The eating of shed epidermal material in squamate reptiles. Herpetologica, 21, 306-308.

Cooper WE, Vitt LJ (2002) Distribution, extent, and evolution of plant consumption by lizards. Journal of Zoology, 257, 487-517.

Daza JD, Herrera A, Thomas R, Claudio HJ (2009) Are you what you eat? A geometric morphometric analysis of gekkotan skull shape. Biological Journal of the Linnean Society, 97(3), 677-707.

Díaz LM, Hedges B (2009) First record of the genus Aristelliger (Squamata: Sphaerodactylidae) in Cuba, with the description of a new species. Zootaxa, 2028, 31-40.

Dunn ER, Saxe Jr LH (1950) Results of the Catherwood-Chaplin West Indies Expedition, 1948. Part V. Amphibians and Reptiles of San Andrés and Providencia. Proceedings of the Academy of Natural Sciences of Philadelphia, $102,141-165$.

English TMS (1912) Some notes on the natural history of Grand Cayman, pp 598-600. In: Ford JC, Cundall F, editors, Handbook of Jamaica for 1912 (Institute of Jamaica, Kingston, Jamaica).

Garman S (1888) Reptiles and batrachians from the Caymans and the Bahamas, collected by Prof. C.J. Maynard for the Museum of Comparative Zoology at Cambridge. Massachusetts. Bulletin of the Essex Institute, 20, 1-13.

Gifford ME, Powell R, Steiner WE (2000) Relationship of diet and prey availability in Aristelliger cochranae, a gecko from Navassa Island, West Indies. Caribbean Journal of Science, 36, 323-326.

Grant C (1931) A new species of Aristelliger from Navassa. Journal of the Department of Agriculture of Puerto Rico, 4, 399-400.

Grant C (1940) The herpetology of the Cayman Islands. Bulletin of the Institute of Jamaica: Science series, 2, 65.

Griffing AH, DeBoer JC, Campbell PD, Wilson BS, Bauer AM (2017) Aristelliger praesignis (Jamaican Croaking Lizard). Maximum Size. Herpetological Review, 48,184-185.

Hecht MK (1952) Natural selection in the lizard genus Aristelliger. Evolution, 6, 112-124.

Henderson RW, Powell R (2009) Natural History of West Indian Reptiles and Amphibians (University Press of Florida, Gainesville, Florida).

Herrel A, Vanhooydonck B, Joachim R, Irschick DJ (2004) Frugivory in polychrotid lizards: Effects of body size. Oecologia, 140, 160-168.

Herrera ERT, Franke R, Knogge C, Skrabal J, Heymann EW (2003) Flower and fruit visitors of Marcgravia longifolia in Amazonian Peru. Plant Biology, 5, 210-214.

Johnson DR (1966) Diet and estimated energy assimilation of three Colorado lizards. American Midland Naturalist, 76, 504-509.

Lee JC (1996) The Amphibians and Reptiles of the Yucatan Peninsula (Cornell University Press, Ithaca).

McCranie JR, Harrison A, Orellana LV (2017) Updated population and habitat comments about the reptiles of the Swan Islands, Honduras. Bulletin of the Museum of Comparative Zoology, 161, 265-284.

Noble GK, Klingel GC (1932) The reptiles of Great Inagua Island, British West Indies. American Museum Novitates, $539,1-25$.

Olesen JM, Valido A (2003) Lizards as pollinators and seed dispersers: an island phenomenon. TRENDS in Ecology and Evolution, 4, 177-181.

Paluh DJ, Bauer AM (2016) Nephrurus sheai (Northern Knob-tailed Gecko). Diet. Herpetological Review, 47, 466-467.

Powell R, Henderson RW, Adler K, Dundee HA (1996) An annotated checklist of West Indian amphibians and reptiles, pp. 51-93.

Schoener TW, Slade JB, Stinson CH (1982) Diet and sexual dimorphism in the very catholic lizard genus, Leiocephalus of the Bahamas. Oecologia, 53, 160-169.

Schwartz A, Crombie RI (1975) A new species of the genus Aristelliger (Sauria: Gekkonidae) from the Caicos Islands. Proceedings of the Biological Society of Washington, 88, 305-315.

Schwartz A, Henderson RW (1991) Amphibians and Reptiles of the West Indies: Descriptions, Distributions, and Natu- 
ral History (University Press of Florida, Gainesville, Florida).

Sokol OM (1971) Lithophagy and geophagy in reptiles. Journal of Herpetology, 5, 69-71.

Thomas R (1966) A reassessment of the herpetofauna of Navassa Island. Journal of the Ohio Herpetological Society, 5, 73-89.

Tschapka M, Helversen VO (1999) Pollinators of syntopic Marcgravia species in Costa Rican lowland rain forest: bats and opossums. Plant Biology, 1, 382-388.

van Roosmalen MGM (1985) Fruits of the Guianan Flora (Utrecht University, Utrecht, Netherlands).

Weldon PJ, Demeter BJ, Rosscoe R (1993) A survey of shed skin-eating (dermatophagy) in amphibians and reptiles. Journal of Herpetology, 27, 219-228.

Whitaker AH (1987) The roles of lizards in New Zealand plant reproductive strategies. New Zealand Journal of Botany, 25, 315-328.

White BA, Gray LN, Pavón-Vázquez CJ, García-Vázquez UO, Harrison AS (2017) Aristelliger georgeensis (Saint George Island Gecko). Diet. Herpetological Review, 48, 637.

Wotton DM (2002) Effectiveness of the common gecko (Hoplodactylus maculatus) as a seed disperser on Mana Island, New Zealand. New Zealand Journal of Botany, 40, 639-647.

Zusi RL, Hamas MJ (2001) Bats and birds as potential pollinators of three species of Marcgravia lianas on Dominica. Caribbean Journal of Science, 37, 274-278.

\section{Appendix}

Specimens examined. Abbreviations: SVL, snout-vent length; $M$, male; $F$, female. Numbers correspond to the following ingested items: Arachnida: 1-Araneae. Gastropoda: 2-Thelidomus aspera (Pleurodontidae). Insecta: 3-Blattodea; 4-Coleoptera; 5-Curculionoidea (Coleoptera); 6-Diptera; 7-Tephritidae (Diptera); 8-Heteroptera (Hemiptera); 9-Homoptera (Hemiptera); 10-Hymenoptera; 11-Apocrita (Hymenoptera); 12-Formicidae (Hymenoptera); 13-Lepidoptera; 14-Lepidoptera, larva; 15-Odonata; 16-Orthoptera; 17-Acrididae (Orthoptera); 18-Gryllidae (Orthoptera). Ericales: 19-Marcgravia domingensis (Marcgraviceae). Miscellaneous: 20-seeds; 21-miscellaneous plant material; 22-stones.

\begin{tabular}{|c|c|c|c|c|}
\hline Catalogue Number & Species & SVL (mm) & Sex & Stomach contents \\
\hline KU 228575 & A. barbouri & 36.7 & $\mathrm{~F}$ & - \\
\hline AMB 9354 & A. barbouri & 38.4 & $\mathrm{~F}$ & $1,4,14,17$ \\
\hline AMB 9352 & A. barbouri & 41.6 & $\mathrm{~F}$ & $1,8,16$ \\
\hline AMB 9355 & A. barbouri & 46.0 & $\mathrm{~F}$ & 1 \\
\hline KU 228605 & A. cochranae & 26.9 & - & - \\
\hline KU 228603 & A. cochranae & 41.6 & - & $1,3,9,15,16,22$ \\
\hline KU 228597 & A. cochranae & 46.7 & $\mathrm{~F}$ & - \\
\hline KU 228585 & A. cochranae & 58.2 & M & - \\
\hline KU 228722 & A. expectatus & 17.2 & - & - \\
\hline KU 228730 & A. expectatus & 25.5 & - & - \\
\hline KU 228734 & A. expectatus & 38.5 & $\mathrm{~F}$ & - \\
\hline KU 228702 & A. expectatus & 41.6 & $\mathrm{~F}$ & - \\
\hline KU 228686 & A. expectatus & 52.8 & $\mathrm{~F}$ & 18 \\
\hline UCM 16183 & A. georgeensis & 33.6 & $\mathrm{~F}$ & $5,7,12,16$ \\
\hline UCM 16184 & A. georgeensis & 52.7 & $\mathrm{~F}$ & 16 \\
\hline KU 070030 & A. georgeensis & 78.9 & $\mathrm{~F}$ & 17 \\
\hline KU 070036 & A. georgeensis & 88.1 & M & $1,16,18$ \\
\hline KU 070027 & A. georgeensis & 95.6 & M & - \\
\hline KU 228758 & A. hechti & 46.4 & $\mathrm{~F}$ & 12 \\
\hline KU 228757 & A. hechti & 86.4 & $M$ & 4 \\
\hline KU 228760 & A. lar & 43.4 & - & - \\
\hline KU 228795 & A. lar & 64.2 & $\mathrm{~F}$ & 16 \\
\hline
\end{tabular}




\begin{tabular}{|c|c|c|c|c|}
\hline KU 228792 & A. lar & 70.9 & $\mathrm{~F}$ & 21 \\
\hline KU 228785 & A. lar & 129.9 & $M$ & 19,21 \\
\hline MCZ R 194571 & A. praesignis & 23.0 & - & - \\
\hline MCZ R 194573 & A. praesignis & 23.8 & - & - \\
\hline KU 228974 & A. praesignis & 46.2 & $\mathrm{~F}$ & 20 \\
\hline MCZ R 194600 & A. praesignis & 46.2 & - & 14 \\
\hline MCZ R 194590 & A. praesignis & 52.3 & M & 10,14 \\
\hline KU 228978 & A. praesignis & 52.5 & $\mathrm{~F}$ & 4 \\
\hline MCZ R 194574 & A. praesignis & 52.6 & $\mathrm{~F}$ & 22 \\
\hline MCZ R 194567 & A. praesignis & 54.0 & $\mathrm{~F}$ & 4 \\
\hline MCZ R 194581 & A. praesignis & 57.9 & M & $1,12,13$ \\
\hline MCZ R 194582 & A. praesignis & 58.1 & $\mathrm{~F}$ & 12 \\
\hline MCZ R 194566 & A. praesignis & 60.3 & M & 14 \\
\hline MCZ R 194591 & A. praesignis & 60.7 & $\mathrm{~F}$ & $2,4,6,12$ \\
\hline MCZ R 194587 & A. praesignis & 60.8 & $\mathrm{~F}$ & 2,14 \\
\hline MCZ R 194588 & A. praesignis & 60.8 & M & 6,14 \\
\hline MCZ R 194577 & A. praesignis & 64.8 & $\mathrm{~F}$ & - \\
\hline MCZ R 194599 & A. praesignis & 64.9 & $\mathrm{~F}$ & $1,4,6,22$ \\
\hline MCZ R 194585 & A. praesignis & 67.3 & $\mathrm{~F}$ & 1,12 \\
\hline MCZ R 194568 & A. praesignis & 68.1 & $\mathrm{~F}$ & $1,2,12,14$ \\
\hline MCZ R 194580 & A. praesignis & 69.7 & $\mathrm{~F}$ & 14,16 \\
\hline MCZ R 194596 & A. praesignis & 71.2 & $\mathrm{~F}$ & 4,10 \\
\hline MCZ R 194757 & A. praesignis & 74.9 & M & $1,6,10,14$ \\
\hline MCZ R 194583 & A. praesignis & 78.5 & $\mathrm{~F}$ & 4,12 \\
\hline MCZ R 194578 & A. praesignis & 83.2 & M & 14 \\
\hline MCZ R 194579 & A. praesignis & 86.5 & M & 4 \\
\hline MCZ R 194584 & A. praesignis & 87.5 & M & - \\
\hline MCZ R 194576 & A. praesignis & 86.5 & M & 4 \\
\hline KU 228995 & A. praesignis & 87.5 & M & 11,12 \\
\hline MCZ R 194595 & A. praesignis & 88.2 & M & - \\
\hline MCZ R 194597 & A. praesignis & 88.3 & M & - \\
\hline MCZ R 194586 & A. praesignis & 89.6 & M & - \\
\hline MCZ R 194593 & A. praesignis & 93.4 & $\mathrm{M}$ & 4,10 \\
\hline MCZ R 194592 & A. praesignis & 96.6 & M & $4,12,13,16$ \\
\hline MCZ R 194591 & A. praesignis & 96.9 & M & 1,12 \\
\hline MCZ R 194598 & A. praesignis & 97.5 & $\mathrm{M}$ & $1,3,6$ \\
\hline MCZ R 194594 & A. praesignis & 98.0 & M & 1,6 \\
\hline
\end{tabular}

